\title{
Trust as an organizational knowledge sharing enabler - validation of the impersonal trust scale
}

\author{
Mika Vanhala \\ LUT School of Business and Management, LUT University, \\ Lappeenranta, Finland
}

\begin{abstract}
Purpose - Contemporary organizations face challenges when they have an increasing need for trust, and yet there are decreasing opportunities for the development of interpersonal trust. Thus, the organizations cannot rely only on that and there is a need for complementary forms of organizational trust. Vanhala et al. (2011) developed the scale for measuring impersonal trust. The purpose of this study is to validate the scale in terms of discriminant and nomological validity as well as to test generalizability.

Design/methodology/approach - The validities and generalizability is tested on two samples from two industries in Finland: a forest company (411 respondents) and ICT company (304 respondents). Confirmatory factor analysis and structural equation modelling are used.

Findings - The scale represents both discriminant and nomological validity. Furthermore, the scale is generalizable in different industries.

Research limitations/implications - A more holistic approach to organizational trust is proposed, and the scale for the impersonal element of the organizational trust is validated.

Practical implications - This paper validates the scale for the less studied impersonal element of organizational trust. To manage and develop organizational trust, all of its dimensions should be measured. The scale validated allows the measurement of the impersonal dimension, and the more refined measure also makes it possible to focus development efforts on certain operational areas.

Originality/value - The scale validated represents a step forward toward the reliable measurement of organizational trust. To the best of the researcher's knowledge, this is the first study to show that previously developed scale is valid and generalizable.
\end{abstract}

Keywords Knowledge sharing, Organizational trust, Scale development, Impersonal trust

Paper type Research paper

\section{Introduction}

During the past 20 years, knowledge management and its role in success of the organizations and how those can gain sustainable competitive advantage have been studied widely (Drucker, 2001; Holsapple and Joshi, 2000). Especially the role of knowledge sharing among members of organizations has gained wide attention within academia (Ansari and Malik, 2017). It has been found that knowledge sharing contributes, e.g. to the formation of

(C) Mika Vanhala. Published by Emerald Publishing Limited. This article is published under the Creative Commons Attribution (CC BY 4.0) licence. Anyone may reproduce, distribute, translate and create derivative works of this article (for both commercial and non-commercial purposes), subject to full attribution to the original publication and authors. The full terms of this licence may be seen at http://creativecommons.org/licences/by/4.0/legalcode
Validation of impersonal trust scale

Received 4 December 2018 Revised 23 January 2019 Accepted 24 March 2019
VINE Journal of Information and Knowledge Management Systems Vol. 50 No. 2, 2020 pp. 349-368 Emerald Publishing Limited
$2059-5891$ DOI 10.1108/VJIKMS-12-2018-0119 
VJIKMS

50,2

novel ideas as well as to how new opportunities are developed (Lin, 2007), and different kind of organizations are constantly trying to provide completely novel or improved goods and services. To be successful in this, they need to create a knowledge sharing culture (Ansari and Malik, 2017). In that, the trust within an organization plays a major role (Lin, 2007; Vanhala and Ritala, 2016).

Within the literature on knowledge management, the role of the trust has been identified as a crucial factor for the success of knowledge management practices (Roberts, 2000; Ford, 2004). Particularly, the role of trust in knowledge sharing has been widely studied (Ozlati, 2015) and recently also, the role of trust in knowledge protection (i.e. how to share knowledge only to right people) has been attracting attention (Olander et al., 2015). Trust within and between organizations both support and enable collaboration and knowledge sharing (Politis, 2003) and, in general, trust is seen as critical in the knowledge-based network economy, especially as it is seen as a lubricant when managing uncertainty, complexity and related risks (Arrow, 1974; Luhmann, 1979).

Previous research has suggested that knowledge sharing in different forms (e.g. intraorganizational communication and information sharing) are essential factors, being both antecedents and consequences in trust building processes within organizations (Lewicki and Bunker, 1996; Whitener et al., 1998; Usoro et al., 2007). In addition, the role of trust has been showed also in the context of knowledge sharing in idea crowdsourcing (Kosonen et al., 2014). Thus, it is evident that trust influences positively on knowledge sharing by both facilitating the effective exchange of knowledge as well as by building healthy and supportive environment for knowledge sharing (Gillani et al., 2018). In other words, if people perceive that the other party is trustworthy, they are more willing to share their knowledge (Alge et al., 2003; Parker et al., 2006).

This "other party" might be another person or even the whole employer organization. However, the previous literature studying the role of trust in knowledge sharing has focused mostly on interpersonal trust (Costa et al., 2001; Holste and Fields, 2010; Ansari and Malik, 2017; Gillani et al., 2018). Yet, to fully cover the effect of trust on knowledge sharing, trust, and especially its impersonal elements, should also be considered as an entity in the organization. The first step toward this is to develop a valid measure to capture impersonal trust (Vanhala et al., 2011) because only what gets measured gets managed (Kianto et al., 2018)

This kind of interpersonal approach is also common in trust research in general, and organizational trust is usually conceptualized and measured as an interpersonal phenomenon, that is, as an employee's trust in his or her co-workers and supervisor or manager. Modern organizations face an increasing need for trust; yet, there are fewer opportunities for the development and maintenance of interpersonal trust so that they cannot only rely on that. They also need complementary forms of trust to enhance knowledge creation, innovation and cooperation. If employees are able to trust their organization, they can trust their future in the organization even if their co-workers and supervisor may change.

The concept of impersonal (or institutional) trust and its underpinnings are not yet clear in research on organizations. The concept has mainly been used in sociology and economics, and more so at the macro level. Researchers interested in organizational trust have only recently started to focus more on the impersonal aspects of trust (Bachmann, 2006; Möllering, 2006; Ellonen et al., 2007). The impersonal dimension refers to employees' trust in firm structures and processes, as well as the fairness of HRM policies and decision-making processes (McKnight et al., 1998; Kramer, 1999; Atkinson and Butcher, 2003; Tan and Tan, 2000; Costigan et al., 1998). 
Researchers are increasingly starting to pay more attention to the dynamics and interplay of trust at different levels. However, there are only few researchers who have attempted to measure the impersonal nature of organizational trust (Tan and Tan, 2000; Costigan et al., 1998; Lee, 2004; McCauley and Kuhnert, 1992; Daley and Vasu, 1998). All of them only measured some dimension of impersonal trust, and thus, there is a lack of a comprehensive scale to measure this phenomenon. In previous studies, impersonal trust is mostly considered trust in the top management (McCauley and Kuhnert, 1992; Costigan et al., 1998; Daley and Vasu, 1998; Clark and Payne, 1997; Tyler, 2003; Mayer and Davis, 1999). Moreover, trust in the employer organization (Tan and Tan, 2000), its competence (Lee, 2004) and its performance (Robinson, 1996) have been measured in previous studies. Hence, there is no comprehensive measurement instrument available to measure the impersonal dimension of organizational trust.

Therefore, this paper proposes that a valid and reliable instrument able to measure impersonal trust comprehensively in the organizational context would contribute both to theory and practice in organizational trust. In this paper, the aim is to show that the scale to measure impersonal organizational trust has both discriminant and nomological validity and that it is applicable to different contexts, cross-validating the scale. The paper shows discriminant validity by comparing models including trust in the supervisor and impersonal trust. Nomological validity is assessed by testing if there is relationship between impersonal trust and job satisfaction as well as commitment. The generalizability of the scale is tested by analyzing groups of respondents, in this case, companies from two different industries and different kinds of respondents (blue-collar vs. white-collar workers). Between the samples from these two companies the paper applies cross-validation techniques and multiple group models (Hair et al., 2006).

\section{Theoretical framework}

\section{Organizational trust}

Theories about different types of trust have been developed. Distinctions can be made based on the nature of the trustee. One can have trust in particular people (i.e. personal trust) or trust in organized systems (i.e. impersonal trust; Maguire and Phillips, 2008). Organizational trust can be seen as interpersonal (Mayer et al., 1995; Costigan et al., 1998; Mayer and Davis, 1999) and as impersonal (McCauley and Kuhnert, 1992; McKnight et al., 1998; McKnight et al., 2002). Interpersonal trust is treated as an issue of lateral trust or individual employees' trust toward other employees and vertical trust or trust toward immediate supervisors (McCauley and Kuhnert, 1992). Interpersonal trust may be based on the competence, benevolence or reliability of the other party. Competence-related trust refers to trust in the other party's skills, abilities and characteristics: people trust those who they believe can solve problems and deliver desired outcomes (Mayer et al., 1995; Whitener et al., 1998). Benevolence-related trust refers to an assumption that a trusted person wants to do good, that is, to act benevolently without egocentric or opportunistic behavior. Trust in the other party reflects an expectation that the other party has good intentions and demonstrates concern for the welfare of others (Mayer et al., 1995; Dirks and Ferrin, 2001). Reliabilityrelated trust refers to the set of principles that the trustor finds acceptable; i.e. one can rely upon the other person's actions and words. It also means expectations that the other party will tell the truth and keep promises (Mayer et al., 1995; Williams, 2001).

The focus in this study is on organizational trust as an impersonal issue (McCauley and Kuhnert, 1992; McKnight et al., 1998; McKnight et al., 2002). Impersonal trust is based on roles, systems and reputation, whereas interpersonal trust is based on interpersonal interaction between individuals within a particular relationship.
Validation of impersonal trust scale 
VJIKMS

50,2

The operational environment of companies is complex, rapidly changing and dispersed, which makes impersonal trust a potential source of competitive advantage. Even if interpersonal trust (e.g. a close supervisory role) is critical, organizations can benefit from fostering complementary impersonal forms of trust. Employees who are able to trust the organization they work for can trust their future in it even if other employees and supervisors cannot provide sufficient support for the evolution of strong interpersonal trust. If employees could trust the organization without having personalized knowledge of each decision-maker and key actor, it would be more efficient (Kramer, 1999). The impersonal dimension of organizational trust is usually called institutional trust. Trust in the organization is the evaluation of an organization's trustworthiness as perceived by employees; that is, confidence that it will perform an action that is beneficial or at least not detrimental to them (Tan and Tan, 2000; Atkinson and Butcher, 2003; Maguire and Phillips, 2008). Employees may draw inferences about institutional trust from the behavior of highly visible role models, for example, in the top management (Kramer, 1999). According to Costigan et al. (1998), most employees base their trust in the top management more on the outcomes of the decisions and less on direct personal experience of the character or actions of the individuals. McCauley and Kuhnert (1992) also point out that trust between employees and the management is not interpersonal in nature but based on roles, rules and structured relations within the organization. Employees also monitor the organizational environment to evaluate whether they will trust the management. If the environment encourages a high level of management trust in employees, the employees will reciprocate by exhibiting high levels of trust in the management. Moreover, according to Blomqvist (1997), trusting a person and trusting an organization are two different things. Trust in an organization is based on the way it acts, on a particular trustworthy way of behaving. This may stem from the manager's personality or from a strongly centralized decision-making structure and organizational culture.

As a summary, it can be stated that organizational trust refers to trust in co-workers and other employees (lateral trust) and trust in supervisors and the management (vertical trust). Lateral and vertical trust can further be divided into trust in the other party's competence, benevolence and reliability. The third dimension of organizational trust is impersonal by nature (impersonal trust) and can be divided into the capability and fairness of the employee organization. The following figure (Figure 1) illustrates the structure of organizational trust.

\section{Development of the impersonal trust scale}

Developing the impersonal trust construct and scale to measure it has followed a path. Vanhala et al. (2011) developed the scale that is especially designed to assess employees' impersonal trust in their employer as an organization. Their aim was to develop a construct and a scale encompassing the impersonal element of organizational trust, which could support and complement the concept of interpersonal trust. In the first phase, a theoretical review of the literature on sociology, socio-psychology, economics as well as multidisciplinary research on trust was conducted to build a sound theoretical basis for the construct of impersonal trust. In addition, the inductive approach was used and employer perceptions of the nature of trust in their organizations (inter-personal vs impersonal trust) were collected in 4 focus group interviews from individuals from 13 organizations. The authors used confirmatory factor analysis on data from 166 respondents with different kinds of organizational backgrounds in Finland to validate the scale. The study presented an impersonal trust construct and a scale to measure it (Vanhala et al., 2011). It suggested that the construct of impersonal trust consists of two dimensions (capability and fairness) and provided eight components for those (see Figure 2). 


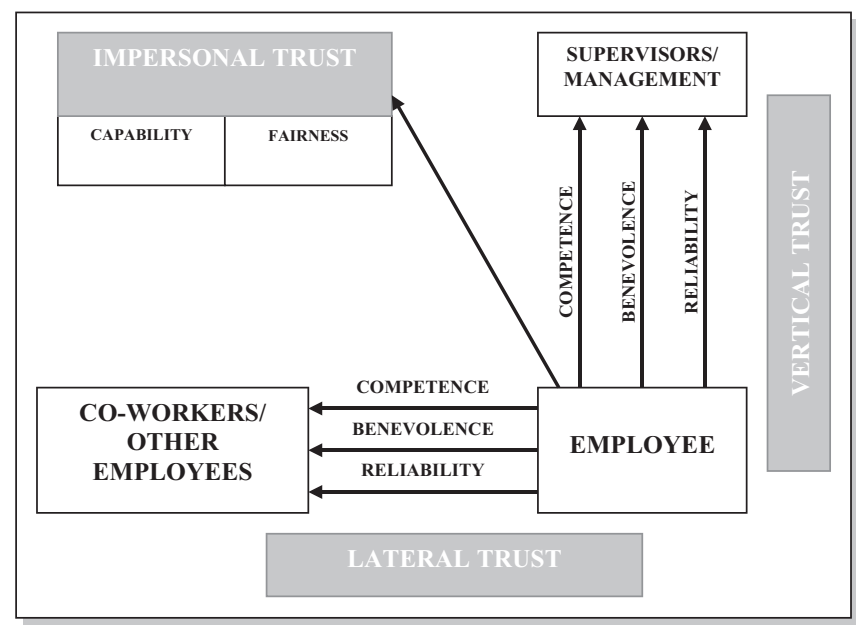

Validation of impersonal trust scale

Source: Adapted from Costigan et al., 1998

Figure 1.

The structure of organizational trustSource: Adapted from Costigan et al. (1998)

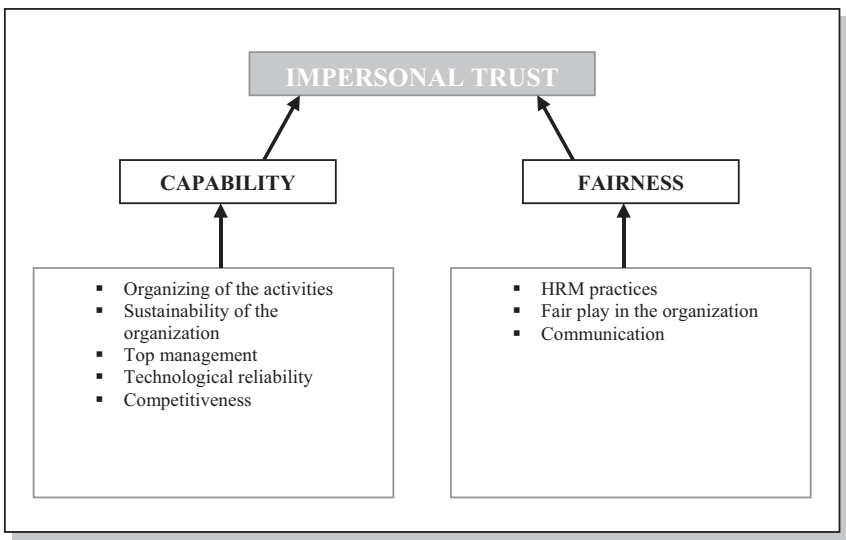

Source: Vanhala et al., 2011

Figure 2. The structure of impersonal trust

Thus, the paper defines the impersonal element of organizational trust as "the individual employee's expectation about the employer organization's capability and fairness". The capability dimension consists of five and the fairness dimension of three components.

The capability dimension:

- organizing of the activities: the general operations, the organization's ability to cope in exceptional situations and how its resources are exploited;

- sustainability of the organization: changes in the operational environment and employment outlook; 


\section{VJIKMS \\ 50,2}

- top management: the top management's capabilities and decision-making practices;

- technological reliability: equipment that is crucial for organization's operations, the respondents' personal tools, working conditions and received assistance with technical problems; and

- competitiveness: the organization's products and services as well as the organization itself compared to its competitors.

The fairness dimension:

- HRM practices: salary, reward systems, education and career;

- fair play in the organization: the top management's behavior, reward systems, the employer's promises and obligations, internal competition and opportunism; and

- communication: trustworthiness and sufficiency of information, information that is relevant and overall internal communication.

The 18 items to measure the capability dimension and its components as well as the 13 items to measure the fairness dimension and its components are presented in Appendices 1 and 2.

This study is a follow-up of work done previously (Vanhala et al., 2011). As a final step of the scale development process, the aim in this paper is to validate the scale for measuring the impersonal dimension of organizational trust. First, the paper shows that the concept of impersonal trust is different from interpersonal trust (discriminant validity). Second, the paper studies the nomological validity of the scale. This is shown by studying whether there are theoretically supported relationships between impersonal trust and its outcomes, that is, an individual employee's job satisfaction and commitment to the employer organization in this case. Finally, the paper shows that the scale is generalizable. This is shown by analyzing groups of respondents, which in this case are companies from two different industries and different kinds of respondents (blue- vs white-collar workers). The paper applies cross-validation techniques and multiple group models between the samples from these two companies (Hair et al., 2006).

\section{Research design}

Data collection and sampling

The following quantitative empirical analysis is based on survey data. The data was collected from 715 respondents from two large companies in forest (Company A) and ICT (Company B) industries in Finland. Sample A is based on a sample of blue-collar workers with a large forestry company in Finland. In total, 700 questionnaires with a covering letter were distributed by the company representatives randomly among the firm's 1,400 employees. We received 411 useable responses from 8 units within 2 of the firm's mills (a 58.7 per cent response rate). Examples of units include paper as well as pulp production and maintenance service. As can be seen from Table I, most of the respondents were men, most had long tenures at the firm and most had not attended tertiary education. On the basis of discussions with the company representatives as well as company annual reports, the demographics of the sample represent the population of the whole workforce.

Sample B is based on a sample of white-collar workers with a large ICT company in Finland. The data were collected from 17 units within 3 R\&D centers. Examples of a unit in this study include software engineering and hardware planning. A covering letter with a personal link to the questionnaire was sent to 1,384 potential respondents via email. A total of 304 completed questionnaires were received, representing a 22 per cent response rate. As can be seen from Table I, men were again in the majority, but this sample was notably younger and 


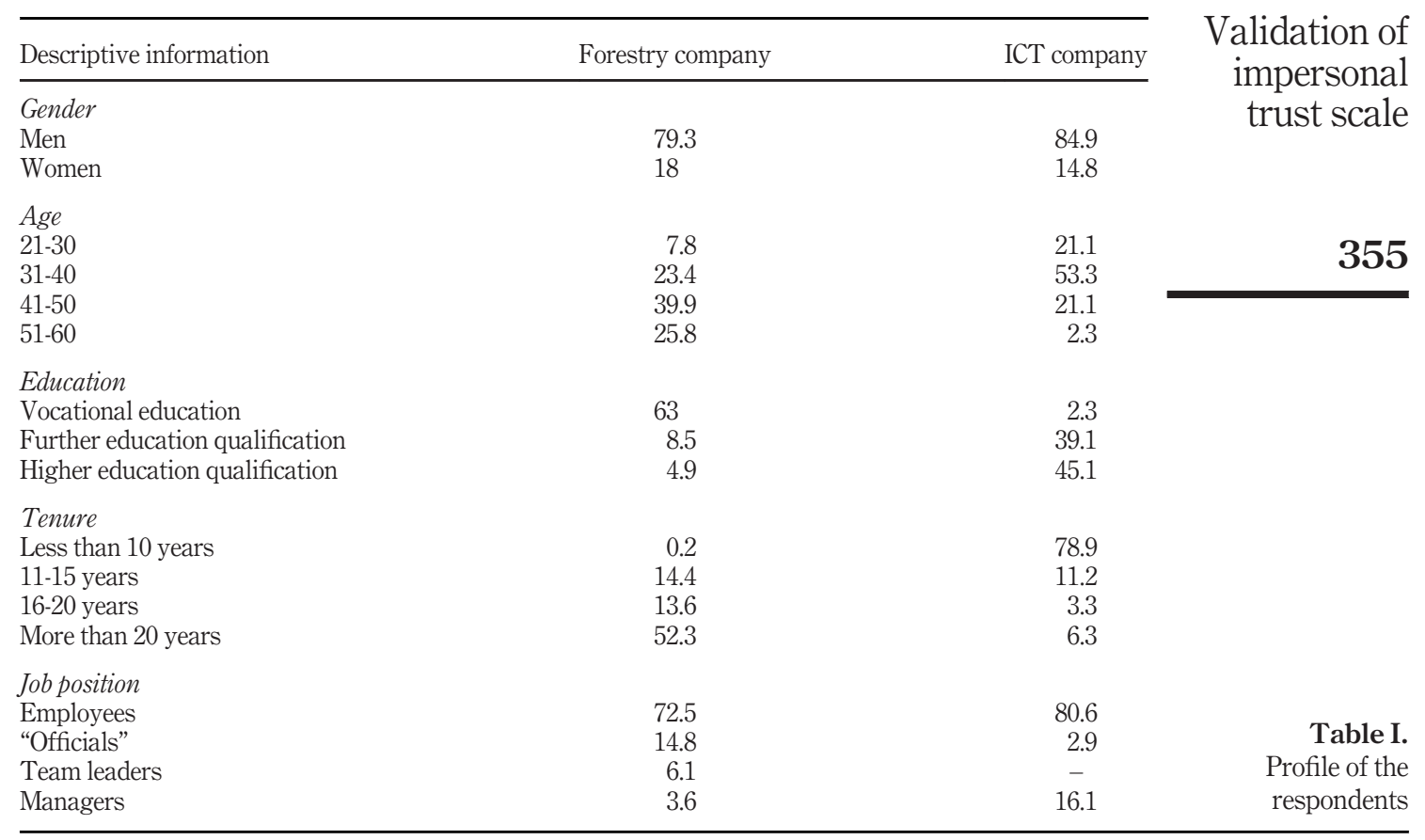

better educated than the forestry workers and had much shorter careers with their current employer. Again, on the basis of both discussions with company representatives and the company's annual report, the sample is representative of the workforce as a whole.

\section{Methods}

As a first step, the measurement model for impersonal trust was validated using confirmatory factor analysis (CFA). CFA was used to test discriminant validity, and structural equation modeling was applied in the assessment of nomological validity. For the purpose of crossvalidation (Hair et al., 2006), a multi-group CFA was conducted. LISREL software was applied for the analysis. CFA was used to analyze generalizability, i.e. measurement invariance between the two samples. A total of 715 cases were processed using LISREL 8.50. The covariance matrix was computed with PRELIS 2.50. The maximum likelihood estimation method was used.

\section{Data analysis}

Discriminant validity

As discussed above, the paper argues that interpersonal trust and impersonal trust are distinct dimensions of organizational trust. Here, trust in the supervisor represents interpersonal trust, and it is measured by 11 items by Mayer $\mathrm{et} \mathrm{al.} \mathrm{(1995} \mathrm{and} \mathrm{Mayer} \mathrm{(1999).} \mathrm{Items} \mathrm{covered} \mathrm{the} \mathrm{competence,}$ benevolence and reliability of the supervisor. (See Appendix 3 for the wording of the items.)

Two competing models were compared to test the discriminant validity of the scale:

(1) Model 1 - the two-correlated second-order factor model: responses to each item are reflective of two factors, a general trust factor (trust in the supervisor or impersonal trust) and a specific component factor. In trust in the supervisor, these component 
VJIKMS

50,2

\section{6}

factors were competence, benevolence and reliability. In impersonal trust, these components were organizing operational activities, the sustainability of the organization, the management of the business and people, technological reliability, competitiveness, HRM practices, fair play in the organization and communication.

(2) Model 2 - the one-factor model: organizational trust is conceptualized as a onedimensional construct and the covariance among the items being accounted for by a single factor.

The summary statistics for these models for both samples are shown in Table II. Model 1 was found to outperform Model 2 on all measures in both samples. Thus, it is shown that trust in the supervisor and impersonal trust are two distinct constructs.

In addition, discriminant validity was evaluated with the method recommended by Anderson and Gerbing (1988). Two models for pairs of trust in the supervisor and impersonal trust constructs were compared. In the first model the constructs were let to correlate freely, and in the second model the correlations were fixed as equal to one. All chi-square difference tests in both samples were significant, which indicates that pairs of constructs correlated at less than one. Thus, there is evidence of discriminant validity (Table III).

In summary, it can be stated that the impersonal trust scale has discriminant validity.

\section{Nomological validity}

Zeffane and Connell (2003) state that the level of trust determines much of an organization's character and, consequently, impacts on such things as the structure of the organization and control mechanisms, job design, effectiveness and the extent of communication, relationships with other organizations, innovation, job satisfaction, commitment, organizational citizenship behavior, goal sharing and coping with crises. Thus, organizational trust has been identified as a critical factor in leadership (Tyler, 2003), job satisfaction (Shockley-Zalabak et al., 2000; Aryee et al., 2002), commitment (Dirks and Ferrin, 2001; Bijlsma and Koopman, 2003) and performance (Barney and Hansen, 1994).

\begin{tabular}{lrccccr}
\hline Model & Chi-square (df) & p-value & RMSEA & GFI & NNFI & CFI \\
\hline Sample $A$ & & & & & & \\
Model 1 & $600.82(338)$ & 0.00 & 0.044 & 0.905 & 0.988 & 0.989 \\
Model 2 & 2487.59(350) & 0.00 & 0.122 & 0.698 & 0.935 & 0.939 \\
Sample B & & & & & & \\
Model 1 & $604.45(338)$ & 0.00 & 0.051 & 0.875 & 0.981 & 0.983 \\
Model 2 & $1946.36(350)$ & 0.00 & 0.123 & 0.685 & 0.930 & 0.935 \\
\hline
\end{tabular}

Table II.

Model comparison

Model 1

$1946.36(350)$

Model

Chi-square (df)

Sample A

Free

$600.82(338)$

Table III.

Constrained

$834.85(339)$

Chi-square difference test for discriminant

Sample B validity

Free

604.45 (338)

Constrained

884.71 (339) 
To test the nomological validity of the scale, this study relies on structural equation modeling and tests the relationship between impersonal trust and two related constructs identified in the literature (job satisfaction and commitment).

Previous literature shows that trust impacts on employee attitudes such as higher job satisfaction and organizational commitment (see reviews by Colquitt et al., 2007; and Dirks and Ferrin, 2001). According to Aryee et al. (2002; see also Bijlsma and Koopman, 2003), trust in the organization is positively associated with employees' organizational commitment, and Tan and Tan (2000) also found a negative association with trust and employees' intention to quit.

In addition, Dirks and Ferrin (2002) ascertained in their meta-analysis that trust had the strongest relationships with job satisfaction and commitment. Studies have also examined the impact of trust on attitudes such as job satisfaction (Aryee et al., 2002). Yet, Colquitt and colleagues' meta-analysis (2007) found that trust is positively correlated with organizational commitment.

Employees' commitment to their employer organization was measured with four items by Cook and Wall (1980). The items covered leaving the organization, pay-related commitment, how recommendable an employer is seen and contribution-related commitment. Job satisfaction was measured as an employee's satisfaction about the job, pay, career progression and future opportunities within the organization. These were assessed by four items from Cook et al. (1981). (See Appendix 3 for the wording of the items.)

The results show (see Table IV) that in both samples trust influences commitment (Sample A: Impersonal trust $\rightarrow$ Commitment $=0.892 ; t=7.653$ and Sample B: Impersonal trust $\rightarrow$ Commitment $=0.668 ; t=6.524$ ) as well as job satisfaction (Sample A: Impersonal trust $\rightarrow$ Job satisfaction $=0.574 ; t=6.257$ and Sample B: Impersonal trust $\rightarrow$ Job satisfaction $=0.599 ; t=$ 6.493). Thus, there is evidence that the scale has nomological validity.

\section{Invariance}

Measurement models and loose cross-validation. CFA was conducted separately for both samples and for both dimensions to test the measurement models and verify that the constructs of the dimensions were, in fact, same in both samples. The latter is one form of cross-validation. This approach is termed as loose cross-validation, in which all of the parameters in a model are reestimated in an independent sample. (see e.g. Hair et al., 2006; Conroy and Motl, 2003).

\begin{tabular}{|c|c|c|c|}
\hline Path & Standardized parameter estimate & $t$-value & \\
\hline $\begin{array}{l}\text { Sample A } \\
\text { Imp } \rightarrow \text { Commit }\end{array}$ & $0.892^{* * * *}$ & 7.653 & \\
\hline $\begin{array}{l}\text { Chi-square }=69.60, \mathrm{df} \\
\mathrm{Imp} \rightarrow \mathrm{JS}\end{array}$ & $\begin{array}{c}\mathrm{SEA}=0.039, \mathrm{GFI}=0.970, \mathrm{NNFI}=0.986, \mathrm{CFI}=0.989 \\
0.574^{* * * *}\end{array}$ & 6.257 & \\
\hline Chi-square $=116.96, \mathrm{~d}$ & $\mathrm{ISEA}=0.065, \mathrm{GFI}=0.951, \mathrm{NNFI}=0.946, \mathrm{CFI}=0.958$ & & \\
\hline $\begin{array}{l}\text { Sample B } \\
\text { Imp } \rightarrow \text { Commit }\end{array}$ & $0.688^{* * * *}$ & 6.524 & \\
\hline $\begin{array}{l}\text { Chi-square }=118.22, \mathrm{~d} \\
\mathrm{Imp} \rightarrow \mathrm{JS}\end{array}$ & $\begin{array}{c}\text { ISEA }=0.076, \text { GFI }=0.934, \mathrm{NNFI}=0.909, \mathrm{CFI}=0.929 \\
0.599^{* * * *}\end{array}$ & 6.493 & Table IV. \\
\hline $\begin{array}{l}\text { Chi-square }=84.46, \mathrm{df} \\
\text { Note: } * * * p<0.005\end{array}$ & $\mathrm{SEA}=0.056, \mathrm{GFI}=0.952, \mathrm{NNFI}=0.960, \mathrm{CFI}=0.969$ & & $\begin{array}{l}\text { The fit indices and } \\
\text { path coefficients of } \\
\text { the models }\end{array}$ \\
\hline
\end{tabular}

Validation of impersonal trust scale

357 
VJIKMS

50,2

\section{8}

First, five components in the capability dimension (three components in the fairness dimension) were tested together in Sample A. In the capability dimension, all items were included in further analysis. In the fairness dimension the initial model fit indices indicated that the original model needed to be re-specified to fit better with the sample data. Three items (Items 6, 8 and 11) were removed (in stages, i.e. one item at a time) according to the values of the standardized residuals with other items. From pairs of items with a large standardized residual the one with lower squared multiple correlation was removed and the one resulting in more improvement in the model fit was retained. Next, these five correlated components (three for the fairness dimension) models were tested with Sample B.

In summary, the various measures of overall goodness-of-fit gave sufficient support to deem the results an acceptable representation of the hypothesized constructs of both components in both samples. (See Table V for the fit indices.)

Validity and reliability of the scales.

Capability. In both samples, the loadings of almost all items for the components of the capability dimension were high and statistically significant (see Appendix 1). All in all, it can be said that all items are related to their specified constructs, verifying the posited relationships among indicators and dimensions. As for construct reliability (CR), all components exceed the recommended level of 0.60 , and therefore, the model provides reliable measurements of the constructs. For the measures of extracted variance (AVE), there are some problems. AVE for some measures fell short of the cutoff of 0.50 .

Fairness. In two components of the fairness dimension (HRM practices and communication), all item loadings were high and statistically significant in both samples (see Appendix 2). CRs and AVEs of these components are also in order. One component (fair play in the organization), however, seems to present some problems. The loadings of the items were quite low (especially Item 7) and the CR and AVE of this component were also low.

In summary, the assessment of the models provided good evidence of validity and reliability for the operationalization of impersonal trust.

Invariance testing. To test the generalizability of the scale more rigorously than loose cross-validation, measurement invariance was examined across the two data subsets to ensure that the respondents from both groups interpret the scale items in the same manner. This was done by cross-validating the scale with groups of respondents, that is, companies from two different industries and different kinds of respondents (blue- vs white-collar workers). Sample A presents Company A (forest industry, blue-collar workers) and Sample $\mathrm{B}$ presents Company B (ICT industry, white-collar workers).

Measurement invariance was assessed using procedures outlined by Steenkamp and Baumgartner (1998). To test the scale on both samples, the measures for configural invariance and for metric invariance were tested. Configural invariance refers to factor structure equivalence between samples. Metric invariance provides indication whether people from different samples interpret and use the scale in the same manner. In more detail, metric invariance provides

Table V.

\begin{tabular}{lcccccr}
\hline Model & Chi-square (df) & p-value & RMSEA & GFI & NNFI & CFI \\
\hline Capability (five correlated factors) & & & & & & \\
Sample A & $338.13(125)$ & 0.00 & 0.064 & 0.916 & 0.918 & 0.933 \\
Sample B & $259.11(125)$ & 0.00 & 0.060 & 0.913 & 0.920 & 0.934 \\
Fairness (three correlated factors) & & & & & & \\
Sample A & $93.48(32)$ & 0.00 & 0.068 & 0.956 & 0.930 & 0.950 \\
Sample B & $60.52(32)$ & 0.0017 & 0.054 & 0.962 & 0.954 & 0.967 \\
\hline
\end{tabular}


evidence that respondents use the rating scales similarly across groups, and differences between values can be compared. (see e.g. Hair et al., 2006; Steenkamp and Baumgartner, 1998).

As suggested by Cheung and Rensvold (1999), each of the components was examined in the model for invariance. A separate model was estimated for each component. In each model, the factor loadings (metric variance) associated with the component were constrained to be equal across groups, while the loadings associated with the other components were not.

Capability. For the capability dimension, the configural invariance model was estimated first. It is the baseline model against which the other models can be compared. The initial model was modified because there were two items with error variance over 1 (Items 9 and 17). The fit of the final configural invariance model was satisfactory (see Table VI). All factor loadings were also significant and high. Thus, it can be concluded that the scale exhibited configural invariance; that is, the factor structure is equivalent between the samples.

The full metric variance was tested by constraining the factor loadings to be invariant across the samples. From Table III, it can be seen that in four components (organizing of the activities, sustainability of the organization, top management and technological reliability), there were no significant increase in chi-square between the models of configural invariance and the models of full metric invariance. Moreover, alternative fit indices were within the suggested limits. Thus, in these four components, full metric invariance was supported, and these dimensions in the capability dimension are metric invariant.

In the competitiveness component, there was a significant increase in the chi-square between the model of configural and the model of full metric invariance (change in chi-square 40.86 and degrees of freedom $1, p<0.05$ ). In this case, conducting the test of partial metric invariance was not possible. To test partial metric invariance, the dimension should contain at least two

\begin{tabular}{|c|c|c|c|c|c|c|c|}
\hline Model & Chi-square (df) & $\begin{array}{c}\text { Change in } \\
\text { chi-square (df) }\end{array}$ & RMSEA & CAIC & NNFI & $\mathrm{CFI}$ & \\
\hline \multicolumn{8}{|l|}{ Organizing of the activities } \\
\hline Configural invariance & $597.25(250)$ & - & 0.062 & 1566.499 & 0.918 & 0.933 & \\
\hline Configural invariance final & $475.11(188)$ & - & 0.065 & 1353.495 & 0.927 & 0.943 & \\
\hline Metric invariance & $476.45(192)$ & $1.34(4)$ & 0.064 & 1324.547 & 0.929 & 0.943 & \\
\hline \multicolumn{8}{|c|}{ Sustainability of the organization } \\
\hline Configural invariance & $597.25(250)$ & - & 0.062 & 1566.499 & 0.918 & 0.933 & \\
\hline Configural invariance final & 475.11 (188) & - & 0.065 & 1353.495 & 0.927 & 0.943 & \\
\hline Metric invariance & $476.52(189)$ & $1.41(1)$ & 0.065 & 1347.334 & 0.927 & 0.942 & \\
\hline \multicolumn{8}{|l|}{ Top management } \\
\hline Configural invariance & $597.25(250)$ & - & 0.062 & 1566.499 & 0.918 & 0.933 & \\
\hline Configural invariance final & 475.11 (188) & - & 0.065 & 1353.495 & 0.927 & 0.943 & \\
\hline Metric invariance & 478.59 (191) & $3.48(3)$ & 0.065 & 1334.526 & 0.928 & 0.943 & \\
\hline \multicolumn{8}{|l|}{ Technological reliability } \\
\hline Configural invariance & $597.25(250)$ & - & 0.062 & 1566.499 & 0.918 & 0.933 & \\
\hline Configural invariance final & 475.11 (188) & - & 0.065 & 1353.495 & 0.927 & 0.943 & \\
\hline Metric invariance & $477.73(190)$ & $2.62(2)$ & 0.065 & 1340.966 & 0.927 & 0.942 & \\
\hline \multicolumn{8}{|l|}{ Competitiveness } \\
\hline Configural invariance & $597.25(250)$ & - & 0.062 & 1566.499 & 0.918 & 0.933 & Model comparison \\
\hline Configural invariance final & $475.11(188)$ & - & 0.065 & 1353.495 & 0.927 & 0.943 & for the capability \\
\hline Metric invariance & 515.97 (189) & $40.86(1)$ & 0.07 & 1386.78 & 0.916 & 0.934 & dimension \\
\hline
\end{tabular}

Validation of impersonal trust scale

359 
VJIKMS

50,2

\section{0}

constrained items (Hair et al., 2006), and the competitiveness component initially includes only two items. Hence, in this component neither full nor partial metric invariance was supported.

Fairness. The configural invariance model was also first estimated for the fairness dimension. The initial model was modified because there were two items with error variance, one with over 1 (Item 9) and one with insignificant error variance (Item 12). After these modifications the fit for the final configural model was satisfactory (see Table VII). On the basis of this and significant and mostly high factor loadings, the configural invariance between the samples is supported.

Full metric variance was tested by constraining the factor loadings to be invariant across the samples. From Table III, it can be seen that in two components (fair play in the organization and communication), there were no significant increases in chi-square between the models of configural and the models of full metric invariance. The alternative fit indices were also within the suggested limits. Thus, in these components full metric invariance was supported.

In the HRM practices component, there was a significant increase in chi-square between the model of configural and the model of full metric invariance (change in chi-square 16.66 and degrees of freedom $3, p<0.05$ ). The examination of the modification indices revealed that the significant increase in chi-square was owing to two items (Items 2 and 3). To test partial metric invariance (Hair et al., 2006) the loadings of these items were relaxed. The statistics for the fit of the model of partial metric invariance are reported in Table III. In terms of chi-square and other indices the fit of this model is not significantly poorer than the fit of the final configural invariance model. Thus, partial metric invariance is supported.

\section{Results}

On the basis of the analysis of the two samples, the scale represents both discriminant and nomological validity. Furthermore, on the basis of both loose cross-validation and more rigorous invariance testing, both dimensions in the scale are invariant between the two samples. In terms of loose cross-validation, the structures of both dimensions are similar in each sample. In terms of configural invariance testing, both dimensions also had factor structure equivalence between the samples.

In the capability dimension four of the five dimensions had metric invariance; that is, people from different samples interpreted and used the scale in the same manner. However, one component (competitiveness) was not fully or partially metric invariant.

\begin{tabular}{lcccccc}
\hline & & Change in & & & & \\
Model & Chi-square (df) & chi-square (df) & RMSEA & CAIC & NNFI & CFI \\
\hline HRM practices & & & & & & \\
Configural invariance & $154(64)$ & - & 0.063 & 659.771 & 0.94 & 0.957 \\
Configural invariance final & $90.02(34)$ & - & 0.068 & 498.924 & 0.935 & 0.960 \\
Metric invariance & $106.68(37)$ & $16.66(3)$ & 0.073 & 492.863 & 0.926 & 0.951 \\
Partial metric invariance & $90.44(35)$ & $0.42(1)$ & 0.067 & 491.766 & 0.937 & 0.961 \\
Fair play in the organization & & & & & & \\
Configural invariance & $154(64)$ & - & 0.063 & 659.771 & 0.94 & 0.957 \\
Configural invariance final & $90.02(34)$ & - & 0.068 & 498.924 & 0.935 & 0.960 \\
Metric invariance & $90.18(35)$ & $0.16(1)$ & 0.067 & 491.516 & 0.937 & 0.961 \\
Communication & & & & & & \\
Configural invariance & $154(64)$ & - & 0.063 & 659.771 & 0.94 & 0.957 \\
Configural invariance final & $90.02(34)$ & - & 0.068 & 498.924 & 0.935 & 0.960 \\
Metricinvariance & $90.4(35)$ & $0.38(1)$ & 0.037 & 491.731 & 0.937 & 0.961 \\
\hline
\end{tabular}

Table VII.

Model comparison for the fairness dimension
90.02 (34)

90.4 (35) 
In the fairness dimension, two of the three components had metric invariance. The third one also got support for partial metric invariance.

In summary, it can be argued that the scale is valid as well as invariant and generalizable in different industries at least in the Finnish context. However, there were some problems in terms of both factor loadings (fairness dimension: fair play in the organization) and partial metric invariance (capability dimension: competitiveness). These should be tested on a new set of data and, if necessary, items in these dimensions should be modified and/or deleted/added.

\section{Discussion}

From the perspective of measurement and scientific inference, it is important to have evidence of different validities as well as measurement invariance (i.e. equivalence). Such evidence is seldom presented in studies on organizational trust. However, to measure something reliably, one should demonstrate the validity of the scale. This study both crossvalidated (i.e. demonstrated that it is generalizable in different industries and with different kinds of employees in the Finnish context) and showed that the scale previously developed has discriminant and nomological validity.

In theoretical and methodological terms, the interest was in organizational trust as a more comprehensive concept incorporating both the interpersonal and impersonal aspects of trust. The construct of impersonal trust (and the scales for measuring it in the organizational context) validated in this study represents a step forward toward the effective and reliable measurement of organizational trust. Despite increasing research attention to this area, to date, no valid and comprehensive operational measure of impersonal trust has been developed. To the best of the researcher's knowledge, this is the first study to provide such a measure that is psychometrically sound and operationally valid.

Recognizing and understanding the impersonal element of organizational trust is important. Moreover, to study, manage and develop organizational trust, all of its dimensions should be measured. The scales developed and validated in this study allow the measurement of the impersonal dimension, and the more refined measure also makes it possible to focus development efforts on certain operational areas. This study provides two major contributions to research on organizational trust: a framework describing the construct of impersonal trust and an instrument for measuring it. This instrument could be applied to investigate, for example, the following aspects:

- The links between the interpersonal and impersonal dimensions of organizational trust.

- Does the role of interpersonal and impersonal trust differentiate in their relationship to knowledge sharing?

- How impersonal trust affects organizational performance or innovativeness?

- How do different kinds of HRM practices affect impersonal trust?

\section{Directions for future research}

The discriminant, nomological and convergent validities of the scale should be tested more intensively in future studies. For example, discriminant validity between the scales of impersonal trust and scales that measure interpersonal trust (i.e. lateral and vertical trust) should be assessed with respondents from different organizational backgrounds and cultures. In addition, to ensure that the construct and the scales can be generalized to different cultures, scales measuring impersonal trust should also be tested in different countries and cultures, and it would also be interesting to test these scales with employees in state administration. Another recommendation

Validation of impersonal trust scale 
would be to test the causal relationships between impersonal trust and other organizational parameters than those used in this study. This would allow the further testing of nomological validity.

In future studies, the validated scale could be used to explore the role on impersonal trust in the knowledge sharing within organizations. As stated above, this avenue of research is still mostly uncovered. By taking all dimensions of the organizational trust into account, it would be possible to get much more detailed and comprehensive understanding about the role of trust in knowledge sharing behavior of the organizational members that have been possible until now.

\section{References}

Alge, B.J., Wiethoff, C. and Klein, H.J. (2003), "When does the medium matter? Knowledge-building experiences and opportunities in decision making teams", Organizational Behavior and Human Decision Processes, Vol. 91 No. 1, pp. 26-37.

Anderson, J.C. and Gerbing, D.W. (1988), "Structural equation modeling in practice: a review and recommended two-step approach", Psychological Bulletin, Vol. 103 No. 3, pp. 411-423.

Ansari, A.H. and Malik, S. (2017), "Ability-based emotional intelligence and knowledge sharing: the moderating role of trust in co-workers", VINE Journal of Information and Knowledge Management Systems, Vol. 47 No. 2, pp. 211-227.

Arrow, K. (1974), Limits of Economic Organization, Norton, New York, NY.

Aryee, S., Budhwar, P. and Chen, Z. (2002), "Trust as a mediator of the relationship between organizational justice and work outcomes: test of a social exchange model", Journal of Organizational Behavior, Vol. 23 No. 3, pp. 267-285.

Atkinson, S. and Butcher, D. (2003), "Trust in managerial relationships”, Journal of Managerial Psychology, Vol. 18 No. 4, pp. 282-304.

Bachmann, R. (2006), "Trust and/or power: towards a sociological theory of organizational relationships in research", in Bachmann, R. and Zaheer, A. (Eds), Handbook of Trust Research, Edward Elgar, Cheltenham, pp. 393-408.

Barney, J.B. and Hansen, M.H. (1994), "Trustworthiness as a source of competitive advantage", Strategic Management Journal, Vol. 15 No. S1, pp. 175-190.

Bijlsma, K. and Koopman, P. (2003), "Introduction: trust within organisations", Personnel Review, Vol. 32 No. 5, pp. 543-555.

Blomqvist, K. (1997), "The many faces of trust”, Scandinavian Journal of Management, Vol. 13 No. 3, pp. 271-286.

Cheung, G.W. and Rensvold, R.B. (1999), "Testing factorial invariance across groups: a reconceptualization and proposed new method", Journal of Management, Vol. 25 No. 1, pp. 1-27.

Clark, M.C. and Payne, R.L. (1997), "The nature and structure of workers' trust in management", Journal of Organizational Behavior, Vol. 18 No. 3, pp. 205-224.

Colquitt, J.A., Scott, B.A. and LePine, L.A. (2007), "Trust, trustworthiness, and trust propensity: a Metaanalytic test of their unique relationships with risk taking and job performance", Journal of Applied Psychology, Vol. 92 No. 4, pp. 909-927.

Conroy, D.E. and Motl, R.W. (2003), "Modification, cross-validation, invariance, and latent mean structure of the self-presentation in exercise questionnaire", Measurement in Physical Education and Exercise Science, Vol. 7 No. 1, pp. 1-18.

Cook, J. and Wall, T. (1980), "New work attitude measures of trust, organizational commitment and personal need non-fulfillment", Journal of Occupational Psychology, Vol. 53 No. 1, pp. 39-52.

Cook, J.D., Hepworth, S.J., Wall, T.D. and Warr, P.B. (1981), “The experience of work”, A Compendium and Review of 249 Measures and Their Use, Academic Press, London. 
Costa, A.C., Roe, R.A. and Taillieu, T. (2001), "Trust within teams: the relation with performance effectiveness", European Journal of Work and Organizational Psychology, Vol. 10 No. 3, pp. 225-244.

Costigan, R.D., Ilter, S.S. and Berman, J.J. (1998), "A multi-dimensional study of trust in organizations", Journal of Managerial Issues, Vol. 10 No. 3, pp. 303-317.

Daley, D.M. and Vasu, M.L. (1998), "Fostering organizational trust in North Carolina: the pivotal role of administrators and political leaders", Administration and Society, Vol. 30 No. 1, pp. 62-84.

Dirks, K.T. and Ferrin, D.L. (2001), "The role of trust in organizational settings", Organization Science, Vol. 12 No. 4, pp. 450-467.

Dirks, K.T. and Ferrin, D.L. (2002), "Trust in leadership: meta-analytic findings and implications for research and practice", The Journal of Applied Psychology, Vol. 87 No. 4, pp. 611-628.

Drucker, P. (2001), “The next society: a survey of the near future”, The Economist, Vol. 2 No. 3, pp. 2-20.

Ellonen, R., Blomqvist, K., Puumalainen, K. and Jantunen, A. (2007), "HRM practices, innovativeness and performance-the mediating role of organizational trust", International Journal of Learning and Intellectual Capital, Vol. 4 No. 3.

Ford, D.P. (2004), "Trust and knowledge management: the seeds of success", in, Holsapple, C.W. (Ed.), Handbook on Knowledge Management, Vol. 1, Springer-Verlag, Berlin Heidelberg, 553-575.

Gillani, S.M.F., Iqbal, S., Akram, S. and Rasheed, M. (2018), "Specific antecedents of employees' knowledge sharing behavior", VINE Journal of Information and Knowledge Management Systems, Vol. 48 No. 2, pp. 178-198.

Hair, J.F., Black, W.C., Rabin, B.J., Anderson, R.E. and Tatham, R.L. (2006), Multivariate Data Analysis, Pearson Education, NJ.

Holsapple, C. and Joshi, K. (2000), "An investigation of factors that influence the management of knowledge in organizations", Journal of Strategic Information Systems, Vol. 9 Nos 2/3, pp. 235-261.

Holste, J.S. and Fields, D. (2010), "Trust and tacit knowledge sharing and use", Journal of Knowledge Management, Vol. 14 No. 1, pp. 128-140.

Kianto, A. Ritala, P. Vanhala, M. and Hussinki, H. (2018), "Reflections on the criteria for the sound measurement of intellectual capital: a knowledge-based perspective", Critical Perspectives on Accounting.

Kosonen, M., Gan, C., Vanhala, M. and Blomqvist, K. (2014), "User motivation and knowledge sharing in idea crowdsourcing", International Journal of Innovation Management, Vol. 18 No. 5, p. 23.

Kramer, R. (1999), "Trust and distrust in organizations: emerging perspectives, enduring questions", Annual Review of Psychology, Vol. 50 No. 1, pp. 569-598.

Lee, H.-J. (2004), "The role of competence-based trust and organizational identification in continuous improvement", Journal of Managerial Psychology, Vol. 19 No. 6, pp. 623-639.

Lewicki, R.J. and Bunker, B.B. (1996), "Developing and maintaining trust in work relationships", in, Kramer, R. and Tyler, T. (Eds), Trust in Organizations-Frontiers of Theory and Research, Sage Publications, London, pp. 114-139.

Lin, H.F. (2007), "Knowledge sharing and firm innovation capability: an empirical study", International Journal of Manpower, Vol. 28 Nos 3/4, pp. 315-332.

Luhmann, N. (1979), Trust and Power, Wiley, Chichester.

McCauley, D. and Kuhnert, K. (1992), "A theoretical review and empirical investigation of employee trust in management”, Public Administration Quarterly, Vol. 16 No. 2, pp. 265-284.

McKnight, D.H., Choudhury, V. and Kacmar, C. (2002), "Developing and validating trust measures for e-commerce: an integrative typology", Information Systems Research, Vol. 13 No. 3, pp. 334-361.

McKnight, D.H., Cummings, L.L. and Chervany, N.L. (1998), "Initial trust formation in new organizational relationships", Academy of Management Review, Vol. 23 No. 3, pp. 473-490.

Maguire, S. and Phillips, N. (2008), "Citibankers' at citigroup: a study of the loss of institutional trust after a merger", Journal of Management Studies, Vol. 45 No. 2, pp. 372-401.
Validation of impersonal trust scale 
VJIKMS

50,2

\section{4}

Mayer, R.C. and Davis, J.H. (1999), "The effect of the performance appraisal system on trust for management: a field quasi-experiment”, Journal of Applied Psychology, Vol. 84 No. 1, pp. 123-136.

Mayer, R.C., Davis, J.H. and Schoorman, F.D. (1995), "An integrative model of organizational trust", Academy of Management Review, Vol. 20 No. 3, pp. 709-734.

Möllering, G. (2006), "Trust, institutions, agency: towards a neoinstitutional theory of trust”, in Handbook of Trust Research, Bachmann, R. and Zaheer, A. (Eds), Edward Elgar, Cheltenham, pp. 355-376.

Olander, H., Vanhala, M., Hurmelinna-Laukkanen, P. and Blomqvist, K. (2015), "HR-related knowledge protection and innovation performance: the moderating effect of trust", Knowledge and Process Management, Vol. 22 No. 3, pp. 220-233.

Ozlati, S. (2015), "The moderating effect of trust on the relationship between autonomy and knowledge sharing: a national multiindustry survey of knowledge workers", Knowledge and Process Management, Vol. 22 No. 3, pp. 191-205.

Parker, S.K., Williams, H.M. and Turner, N. (2006), "Modeling the antecedents of proactive behavior at work", The Journal of Applied Psychology, Vol. 91 No. 3, pp. 636-652.

Politis, J.D. (2003), "The connection between trust and knowledge management: what are its implications for team performance", Journal of Knowledge Management, Vol. 7 No. 5, pp. 55-66.

Roberts, J. (2000), "From know-how to show-how? Questioning the role of information and communication technologies in knowledge transfer", Technology Analysis and Strategic Management, Vol. 12 No. 4, pp. 429-443.

Robinson, S.L. (1996), "Trust and breach of the psychological contract", Administrative Science Quarterly, Vol. 41 No. 4, pp. 574-599.

Shockley-Zalabak, P., Ellis, K. and Winograd, G. (2000), "Organizational trust: what it means, why it matters”, Organization Development Journal, Vol. 18 No. 4, pp. 35-48.

Steenkamp, J.-B.E.M. and Baumgartner, H. (1998), "Assessing measurement invariance in crossnational consumer research”, Journal of Consumer Research, Vol. 25 No. 1, pp. 78-90.

Tan, H.H. and Tan, C.S.F. (2000), "Toward the differentiation of trust in supervisor and trust in organization”, Genetic, Social, and General Psychology Monographs, Vol. 126 No. 2, pp. 241-260.

Tyler, T.R. (2003), “Trust within organisations”, Personnel Review, Vol. 32 No. 5, pp. 556-568.

Usoro, A., Sharratt, M.W., Tsui, E. and Shekhar, S. (2007), "Trust as an antecedent to knowledge sharing in virtual communities of practice", Knowledge Management Research and Practice, Vol. 5 No. 3, pp. 199-212.

Vanhala, M. and Ritala, P. (2016), "HRM practices, impersonal trust and organizational innovativeness", Journal of Managerial Psychology, Vol. 31 No. 1, pp. 95-109.

Vanhala, M., Puumalainen, K. and Blomqvist, K. (2011), "Impersonal trust-the development of the construct and the scale", Personnel Review, Vol. 40 No. 4, pp. 485-513.

Whitener, E.M., Brodt, S.E., Korsgaard, M.A. and Werner, J.M. (1998), "Managers as initiators of trust: an exchange relationship framework for understanding managerial trustworthy behaviour", Academy of Management Review, Vol. 23 No. 3, pp. 513-530.

Williams, M. (2001), "In whom we trust: group membership as an effective context for trust development", Academy of Management Review, Vol. 26 No. 3, pp. 377-396.

Zeffane, R. and Connell, J. (2003), "Trust and HRM in the new millenium”, International Journal of Human Resource Management, Vol. 14 No. 1, pp. 3-11.

\section{Further reading}

Demartini, C. (2015), "Relationships between social and intellectual capital: empirical evidence from IC statements", Knowledge and Process Management, Vol. 22 No. 2, pp. 99-111. 
VJIKMS

50,2

366

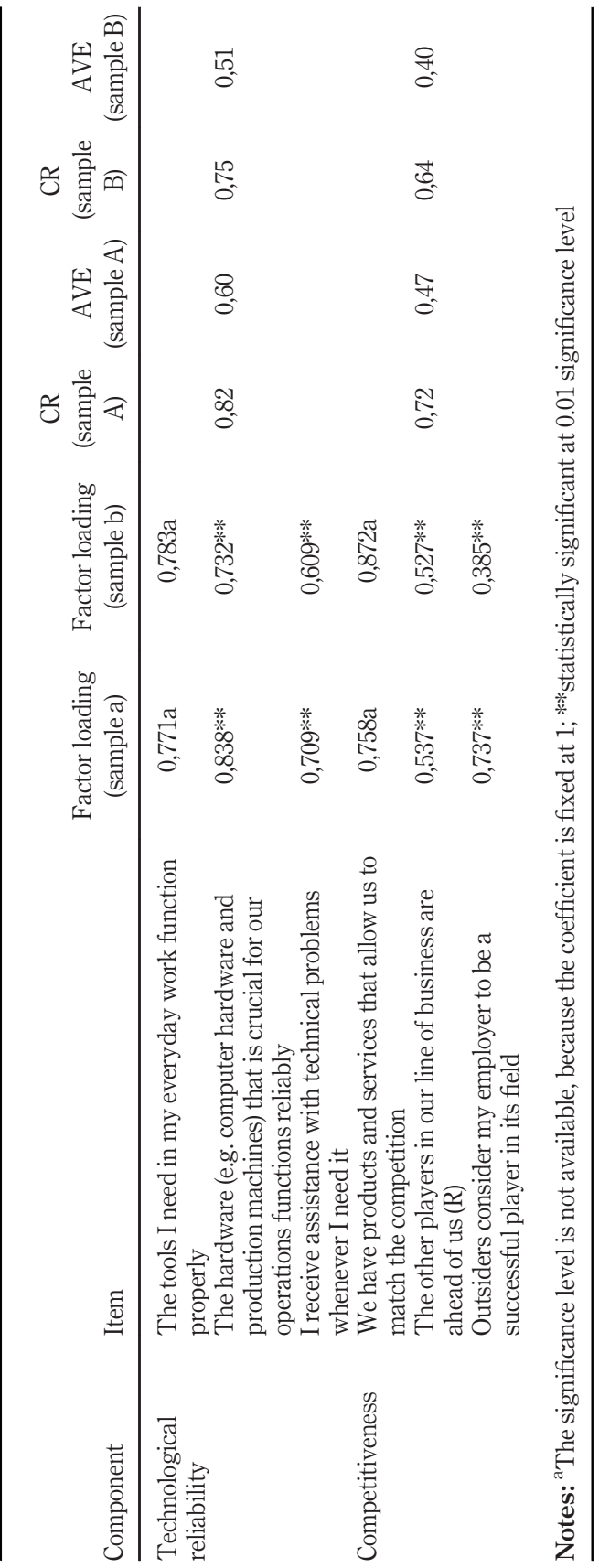

Table AI. 


\section{Appendix 2}

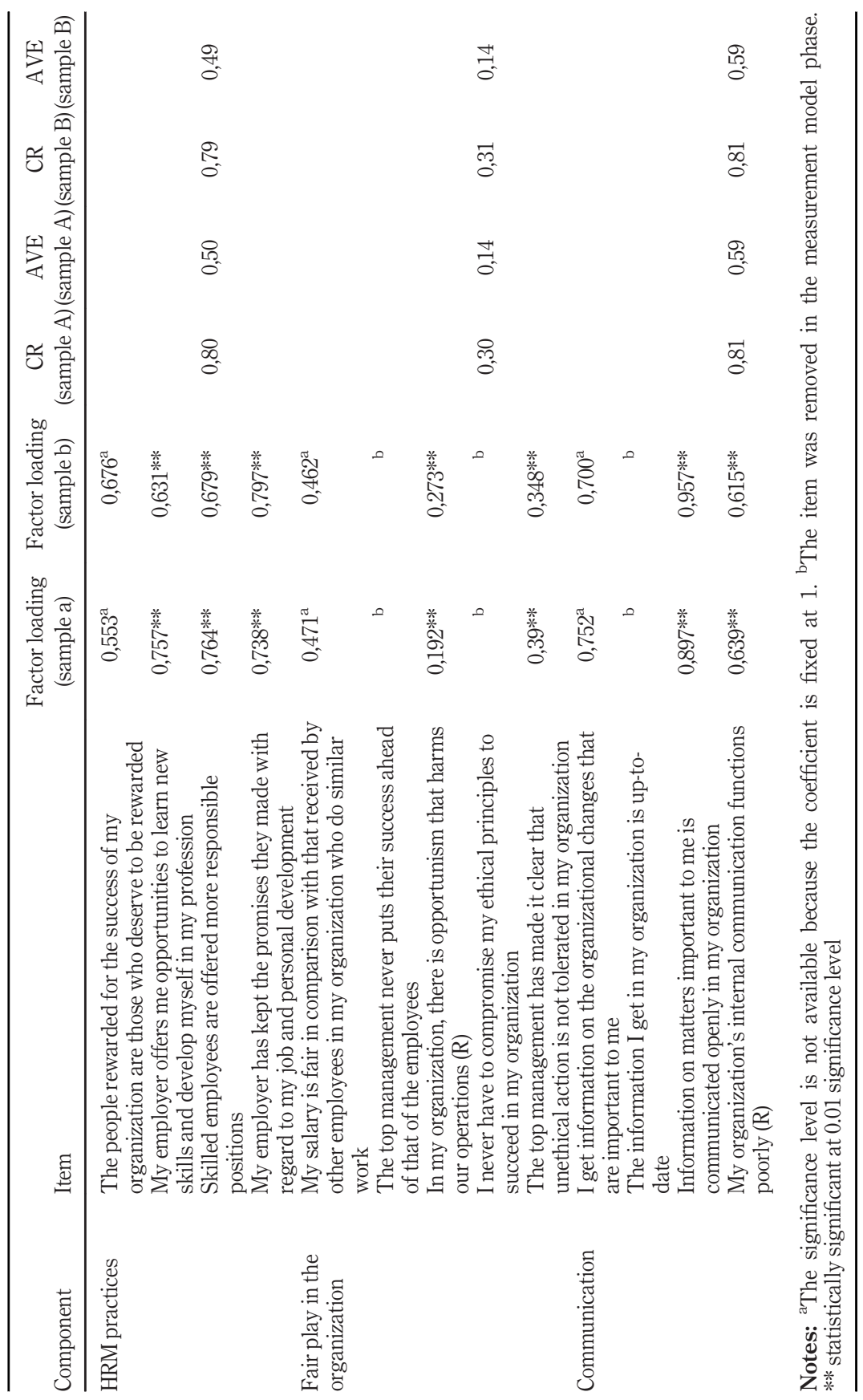

Validation of impersonal trust scale

367

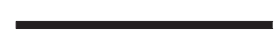

Table AII

Measurement items for the fairness dimension 
VJIKMS

50,2

\section{8}

Table AIII.

Commitment

Measurement items

for trust in the supervisor, job satisfaction and commitment

\section{Appendix 3}

Construct
Trust in the supervisor Competence

Item

The managers in my unit have a lot of knowledge on the work that needs to be done

The managers in my unit are known to be successful in what they do

I feel very confident about the skills of the managers of my unit

Benevolence The managers in my unit are concerned with my welfare

The managers in my unit would not knowingly do anything to hurt me

A typical manager in my unit is sincerely concerned with the problems of others

Most of the time, the managers try to be helpful rather that just look out for themselves

Reliability The managers in my unit try hard to be fair in dealings with others

The actions and behavior of the managers in my unit are always consistent

Integrity is a key value in the operations of the managers of my unit

Job satisfaction

In general, most managers in my unit keep their promises

All in all, I am satisfied with:

My job

My pay, considering my skills and the effort I put into my work

My career progression in this organization so far

The opportunities I have to develop myself and move to new roles in this organization

I sometimes feel like leaving this organization for good (R)

If I were offered a bit better compensation with another employer I would not seriously think of changing my job I would not recommend a close friend to join this organization (R)

Knowing that my work has made a contribution to the good of the whole organization pleases me

\begin{abstract}
About the author
Mika Vanhala, DSc (Econ and Bus. Adm.) is an Associate Professor at the LUT School of Business and Management, LUT University, Finland. His primary research interest is the relationship between HRM practices, organizational trust and organizational performance. Mika's research has been published in journals such as Human Resource Management Journal, Journal of Managerial Psychology and Personnel Review. Mika Vanhala can be contacted at: mika.vanhala@lut.fi
\end{abstract}

For instructions on how to order reprints of this article, please visit our website: 